\title{
Development of a Child during the Third-Year Crisis and Ways to Preserve his Psychological Health in the Family
}

\author{
Aksana Nikolaevna Yashkova
}

Mordovian State Pedagogical Institute, Students Street, 11, Saransk, 430007, Russian Federation

\section{Doi:10.5901/mjss.2015.v6n3s2p333}

Abstract

The third-year crisis is a crucial period of psychosocial development of a person. To preserve and strengthen psychological health of a child, adults have to create special conditions for interaction and communication with a child. These include various activities with the child and establishment of positive emotional contact between parents and the child, taking into account the age-specific and individual features of the child while controlling his behavior in the family, outside the family and in other situations.

Keywords: third-year crisis, psychological health, early age, age crisis.

\section{Introduction}

\subsection{Introduction in the problem}

The problem of productive mental development of a young child (1-3 years old) remains relevant at the current stage of development of age psychology in Russia. This is due to high labor employment of parents (mothers) who return to work soon after giving birth to fully financially provision their families; to the unstable situation with the content and methods of parenting at preschool institutions because of the transformations of the modern education; to the large flow of information (stimuli, technical tumors, etc.), which stimulates the child, but which the parents do not have time to filter, and many more. All of the above more often adversely affects the psychological health of the child, as it does not build trust and positive emotional communication with the parents and teachers; there is a dissonance between the needs of children and of adults in today's information technology environment, the process of the child's self-expression is limited. And the critical periods of development of children indicate the quality of parenting in the family and the level of psychological health (Ruskina, E.N., 2011, Yashkova, A.N., 2012).

\subsection{About the psychological health}

Psychological health is a complex formation, which at the current stage is important for people of all ages, especially for children. From the point of view of O.V. Khukhlaeva, psychological health is a fully fledged mental functioning at the stages of age development, which provides harmony between the different aspects of the inner world of a human and between a human and the society (Khukhlaeva, O.V., 2003).

Theoretical analysis of the domestic (Vygotsky, L.S., 1997, Rean, A.A., 2002, Khukhlaeva, O.V., 2003) and Western literature (Santrock, J., 1996, Sears, R., 1957, Slobodskaya, H., 2005, Goodman, R., 2005) shows that for such fully fledged mental development, all stage of the childhood are important, since they give rise to psychological formations, improve appearing personal characteristics, perpetuate the system of social relations. The latter in its turn determines the process of adaptation and formation of the child's personality, the level of his psychological health (Santrock, J., 1996, Levin, H., 1957, Glenda MacNaughton, 2003).

Some authors (Prokhorova, S.Y. and Khizhova, E.B., 2012) give the following characteristics to the portrait of a psychologically healthy child:

- the child experiences the feelings of affection, tenderness, and love in response to similar feelings of parents;

- fulfills his need for authority and respect, understanding on the part of relatives and important people;

- has a stable sense of "Ego", is active, has an age-appropriate level of aspirations and opportunities;

- is capable of empathy;

- shows no expressed feelings of jealousy and envy; 
- has the leading feeling -good will to people;

- $\quad$ is sociable, seeks to interact with his peers on an equal footing;

- age "crises" pass naturally, painlessly; the typical age-specific problems are solved.

Of course, not everyone has psychological health, as often the child or the adult may be bothered, burdened, annoyed with something, and so on. The signs of psychological health disorders, for example, are: intrapersonal conflicts, internal discomfort, withdrawal, proneness to conflicts with others, difficulties of joint activities, etc. Such changes in human mental development can occur for various reasons, one of which is age crises, the inevitable periods of the child's life (Khukhlaeva, O.V., 2003, Goodman, G. et al, 2005).

The level of psychological health, dynamics, and the result of mental formation are determined by domestic scientists and specialists (neurologists, psychologists, psychotherapists, and teachers) by the nature of the flow and productivity of the crisis period of age development.

\section{Body of the Work}

\subsection{Understanding of the crisis of age development}

Development crises have several names: age crises, crises of age development, age-specific crises, and to date remain an urgent topic for scientific study and psychological counseling in practice. Age psychology has no consensus on the understanding of age crises, their place and role in the mental development of a child.

The crisis of age development must be distinguished from a person's personality crisis. The former arises from the age-specific dynamics of the psyche, and the latter -as a result of occurring socio-psychological circumstances, in which a person finds himself to his own surprise and which provide him with negative experiences, resulting in the internal restructuring of the psyche and behavior.

L.S. Vygotsky understood the crisis of age development as the concentration of capital and abrupt shifts, changes, and fractures in the personality. He called crisis a turning point in the normal course of the child's mental development (Vygotsky, L.S., 1997). They identify several critical stages like this in childhood: during the neonatal period, at 1 year, 3 years, 13 years, and 17 years of age.

The third-year crisis is said to be the stage of ontogeny, accompanied by sharp and radical restructuring of the existing personal neoplasms in children and the transition to a new type of relationship with others (Dandarova, Zh.K., 2002). Basically, we are talking about the changes that take place in the consciousness of a two-year-old child, his physical separation from the mother (parents), and psychological isolation by himself in the world of things. Such a child begins to show more and more his Ego and the need for his recognition and respect by the closer circle (adults).

\subsection{Parties of the crisis of age development}

Regardless of external circumstances and desires of a human, the age development crisis comes suddenly, including on the brink of the early and pre-school ages (the third-year crisis). Though for some people, it passes less painfully and for others -openly and violently (emotionally).

As experience shows, the development crisis at three years of age has two sides. The first one -the negative, destructive side, as the crisis occurs uneasily with the advent of negative emotions, feelings, behaviors in the behavior of the child. It is not desirable and is very dangerous for the psychological health of the young human. As a result, negative characteristics of the personality and interpersonal interaction (with peers, family members, parents) may be formed, and dissatisfaction of the new needs (the needs for respect and recognition) brings the child to the repeated (or extended) critical state of development (Bolotova, A.K., 2012, Yashkova, A.N., 2012).

The other side of the third-year crisis is the positive, constructive one. It signals the emergence of positive changes (new mental structures and new social situation of development) that make up the meaning of each critical period. Positive transformation of the psyche and human behavior occurs with a favorable course of the crisis, which contributes to the formation of the adaptive level of psychological health of the child (Malkina-Pykh, I.G., 2005; Elkonin, D.B., 1997).

Thus, the crisis of development is a sensitive stage in the transformation of the psyche, where the line between its normal and impaired development is very thin. In what direction the crisis will resolve often depends on the efficiency of interaction of the person (the child) with the environment, which determines the individuality of the course of age crisis and a greater role of the family. 


\subsection{Development of a young child}

\subsubsection{Peculiar features of development of the cognitive sphere of a three-year-old child.}

Early childhood in the domestic psychology is defined by the period from 1 to 3 years of age. Development of a child of this age is fast and has positive results for the subsequent age stage.

By the end of this period, children actively manifest the cognitive sphere, namely, they are busy with learning the world of the surrounding things (objects, phenomena, relations); the development of logical operations (analysis, synthesis, comparison, classification, generalization) and visual-active thinking begins. Children are interested in mastering the spoken language, its phonetic, phonemic, and grammatical parties, improving vocabulary and semantics of speech, identifying the relation between the speech and the thinking, where the speech becomes an intellectual function and develops the thinking.

As for the perception function, the formation of perceptual processes and sensory standards (shape, color and quantity) takes place. Attention is still unstable, rapidly switching, and involuntary. The memory of a young child is characterized by involuntariness and short duration, which is manifested so intensively that in the future people face the childhood amnesia phenomenon (the phenomenon of the psyche that adults do not remember the events of the first 3-4 years of life).

In general, children are described as cognitive and observant, often imitate adults, and experience greater need for communication with them (Fadeeva, O.V., 2011; Elkonin, D.B., 1997).

\subsubsection{Peculiar features of development of the personality formations of a three-year-old child.}

Big changes can be noticed in the personality sphere of a three-year-old child, namely, the understanding of oneself as a personality and the separation of oneself from other people takes place. The sense of Ego and the "primary egoism" occur in the behavior, where the opinion of the child cannot be challenged or ignored from his point of view. There is a need for autonomy, and even in their speech children use the phrase "I can do it myself".

The (often inflated) self-esteem is being formed intensively. There is a rapid change of emotions, which are characterized by the liveliness and openness; some of the social feelings develop, for example, pride, shame, empathies. Young children are straightforward and forgiving. They create the first impressions of the people's mood. The motivational sphere develops based on the need for independence, communication, active interaction with adults or objects (toys), etc. The above characteristics can be found in publications of many scientists (Bolotova, A.K., 2012, Vygotsky, L.S., 1997, Fadeeva, O.V., 2011, Elkonin, D.B., 1997, Yashkova, A.N., 2011, etc.).

We can say that a three-year-old child actively joins the social life of a human.

\subsubsection{Peculiar features of development of the social sphere of a three-year-old child.}

The assimilation of the social system of relations by a three-year-old child is based on communication and interaction with adults, and that is why it is necessary for the parents to be close and to actively contact the young child. Under such circumstances, the joint activity of children and adults becomes specific; children easily contact their peers and expand their social circle. Communication is described by emotionality and openness to both adults and other children.

The child actively learns the rules of using the household items and shows great interest to it. Also, the productive and symbolic activity of the child starts, in which the three-year-old child uses paints, clay, pencils, markers, and creates images taken from the reality (Vygotsky, L.S., 1997; Elkonin, D.B., 1997).

The personality characteristics manifest themselves through the formation of self-help skills, especially when eating, during the morning and evening toilets, dressing and undressing, etc. In everyday and communicative situations, the primary assimilation of the moral standards of communication and interaction with objects is observed, as a result of which such characteristics as kindness, thrift, respect, patience, tidiness, etc. can be formed (Fadeeva, O.V., 2011; Yashkova, A.N., 2011).

\subsection{Causes of the third-year crisis}

So why does the development crisis happen at the age of three? What are the causes of the "strange" behavior of a three-year-old child? This, of course, has been studied by the domestic psychology; and here is what they found out.

The third-year crisis is one of the most difficult moments in the life of a child. It is based on the breakdown of the 
close relationship that has existed between the child and the adult (the parents) until the age of three (Vygotsky, V.S., 1997).

By the end of the early age, the breakdown of the close relationship of the child and the parents is associated with the emerging trend towards autonomous activity, and it indicates the fact that adults are no longer limited to the child by the object or the mode of action with it, and for the first time become open to the child, act as carriers of sample actions and relations in the surrounding world.

The "I can do it myself" phenomenon means not only the appearance of the outwardly visible autonomy, but at the same time separation of the child from the adult, which parents most often do not like. They are not prepared to see the child autonomous and cannot painlessly allow him to cut bread, pour water, move a chair, take on a shirt, get a book from the bookshelf, etc. All this can be dangerous for the child's life, of poor quality, and slow compared to the level of an adult, etc. This happens in most families and paves the way for the emergence of psychological contradiction for a three-yearold child between "I want" and "I may", which triggers the crisis phenomena.

According to Vygotsky, L.S, 1997 and Elkonin, D.B., 1997, the internal contradictions are the driving force of mental development, qualitative changes which occur during the crisis periods of age, indicating the transition to the next stage of development.

\subsection{Symptoms of the third-year crisis}

The change of the child's position requires the relatives (parents) to timely adjust to it. And if the new relationship does not form, then the crisis phenomena actually take place. They were first described by Elsa Köhler, but currently other authors (Abrosova, N., 2013, Bolotova, A.K., 2012, Dragunova, T., 1996, Tomas, V.Yu, 2014, and others) have confirmed it. Several important symptoms of the third-year crisis are singled out:

- negativism (it is negative reaction associated with the attitude of one person to another, for example, the child refuses to comply with certain requirements of adults and does the opposite);

- stubbornness (it is a reaction to one's own decision, for example, the child insists on his claim, on his decision, that is, the personality is singled out and the demand to consider this personality is advanced);

- obstinacy (it is a protest against the order, traditions that exist in the home and are adopted by the senior family members, but which hinder and prevent from the fulfillment of his Ego);

- self-will (the aspiration for emancipation from the adult, for example, the child wants to do something by himself without anyone's permission or approval; it partly reminds of the first-year crisis, but in that crisis, the child sought physical autonomy, where in this case we are talking about deeper formations -autonomy of intention, idea in the activity, communication, a certain choice);

- depreciation of the authority of adults and of what used to be interesting and important (traditions, toys, etc.), i.e. loss of interest and even appearance of irritation with regard to the usual and favorite things, people;

- protest-riot, which is expressed in frequent quarrels and conflicts with parents on different occasions;

- aspiration to despotism (aggressive, cold-blooded, authoritarian behavior, which manifests itself in a family with an only child, when he wants to dominate all others and dictates its intentions to the people around).

The above symptoms are typical for most children in the third-year crisis. Parents must see in them a signal of, on the one hand, psychological growth of the child, and, on the other hand, change of the system of relations with him.

\subsection{Phases of the third-year crisis}

The symptoms of the third-year crisis do not immediately manifest themselves in the behavior of a child. They, like other mental formations should mature, which occurs gradually, consistently, and with the account of the social conditions of development. Vygotsky, L.S., 2004, singled out the phases of manifestation of age crises, which can also be considered in relation to the third-year crisis.

I. Pre-crisis. There is a contradiction between the environment and the person's attitude to it. The pre-crisis state is characterized by the internal state of transition, where the rates of affective and cognitive spheres become oppositely directed. The intellectual interest and control reduce, and at the same time the sensitivity to the world around, emotionality, aggression, psychomotor disinhibition or lethargy, isolation, and so on increase.

II. The crisis itself. At this phase, temporary maximum exacerbation of psychological problems of personalized and interpersonal nature takes place, where a certain degree of deviation from the age standard in psychophysical development can be observed. Such phenomena often take place as low cognitive activity, psychological lability (instability), decreased communicativeness, loss of stability of the psyche, mood and 
motivation (motives) swings. In general, it is difficult to reach any agreement with the child during this period, to refocus him on something else, etc.

III. Post-crisis. It is time to resolve conflicts through the formation of a new social situation of development, harmony between its components. As a result of this harmony, relations between the child and his parents normalize, and the affective and cognitive components of the psyche become unidirectional. "Old formations" move to the unconscious, and neoplasms of the psyche move forward to the new level of the consciousness.

The phases of the third-year crisis are to help adults to timely assess the social situation of the child's development, to adjust to new relationship with him, accept his "growing up", and together overcome the difficulties of the age.

\subsection{The behavior of the parents of a child during the third-year crisis}

We need to note that currently, there are practical recommendations for adults for efficient interaction with children during crisis stages (Abrosimova, N., 2013, Dragunova, T., 1996, Malkina-Pykh, I.G., 2005 Tomas, W.Yu, 2014, Yashkova, A.N., 2012). And it is a good fact, as parents must be mentally competent to maximally preserve the psychological health of the child in the family.

Abrosimova N., 2013, in her article said "After all, the main point in a development crisis is not how it flows, but what it results in. Therefore, the main task of parents in such a situation is to trace new features in the child's behavior...", show happiness and pride of the changes, as they are the signs of normal development.

"The period of stubbornness and negativism" is a crisis for both the adult and the child himself. He shows a lot of negative emotions due to frequent bans, while young children are very sensitive and vulnerable. They objectively cannot always be "good". It is very important for them to know where to drain the accumulated tension in the form of anger, resentment, and fear. And one must not try to convince a child that "good girls never get angry" or "one cannot offend his mother", and so on, but to show him the allowed methods of disposing of negative emotions. For example, emotions such as resentment and anger can excellently be relieved in outdoor games (throw the ball, have a fight with balloons, play chants, and others.)

In addition, one needs to show that the mother and father in all situations love him, seek to understand and maintain him. And then he will be more open and feel confident in the family. Encouraging by the parents of the child's desires to make his own decisions and allowing him to make free choice most quickly forms his responsibility and trust. At that, of course, we must remember that the organization of a safe space for the child is the entirely parents' responsibility.

Adults also need to understand that conflicts with the child on several occasions during the third-year crisis are inevitable, but they must not undermine his psychological health. A personality cannot be healthy if it has to constantly hide its own needs inside, anxiously tries to guess the opinions of others and to act in a manner to seem good for everyone. This inevitably results in the development of child's neuroses (Tomas, V.Yu, 2014; Nikorchuk, N., 2014).

In this article, we also offer parents particular ways to preserve the psychological health of the child during the early age crisis. We have singled out the following ways:

- to show the child a possible method of dealing with objects;

- to meet the requests of the child in joint activity;

- not to suppress the initiative of the child, but to support and implement it together;

- to promote and organize the child's autonomy;

- to prohibit only what is dangerous for the life of the child and others, to do it consistently;

- to anticipate the actions of the child (that are not desirable for the parents) and gently switch his attention to other objects (no less important for the child);

- not to be aggressive against the whims and obstinacy of the child;

- to demonstrate love for the child in all situations;

- to show patience and tolerance;

- to be consistent when lodging requirements to the child, to make all family members to comply with them;

- to explain why it is impossible for children to feel the margins of what is permitted, the social standards within the family.

These recommendations still need to be supplemented by the rules that were outlined by Nikorchuk N., 2014. They concern the use of the word "forbidden":

1) there should be a few prohibitions, so that the child would have the opportunity to choose the behavior patterns and develop the self-control function; 
2) prohibitions are to be told kindly, but firmly, not allowing the child to blackmail in order to achieve his goals; this is best done by switching the child's attention to something else;

3) the recommendation is to use the word "forbidden" at the child rarely, and alternate it with other forbidding words: "No, let us..." "Wait, let us ask permission ...".

Thus, the period of the third-year crisis may be called a serious challenge for parents and children, where they learn a lot from each other.

\section{Conclusion}

In conclusion, we would like to note that preserving the psychological health at an early age becomes difficult as the child interacts with the family, in which parents are often busy, with the ever-changing information environment, which affects his psyche that has weak protection mechanisms. A three-year-old child has many developed and still immature mental formations, and the personality just begins to obtain social forms of thinking and behavior, which characterizes the level of psychological health of the child.

The cause of the third-year crisis is the development of the sphere of self-perception of the child and the limited capacity of its manifestation in the social environment. The maturing internal contradictions of a three-year-old child determine the crisis manifestations, which are characterized by negativism, stubbornness, obstinacy, willfulness, depreciation of the adults' authority, and in some cases despotism in the behavior. Such behavior is difficult for the parents to accept in the family and requires them to rebuild their attitude to the "grown-up" child.

The third-year crisis is a sensitive stage in the transformation of the psyche, where the line between its normal and impaired development is very thin. In what direction the age crisis is resolved most often depends on the efficiency of the child's interaction with the parents, which defines the further level of psychological health of the child.

Having successfully overcome the third-year crisis, the child becomes relatively independent from his environment. He recognizes himself as an individual, and moves rather nimbly and independently, can discuss many of his thoughts and needs in the family.

The child who has overcome the third-year crisis gains experience of evaluating himself from the side of the adults, joint activities with them, as well as the satisfaction of his Ego, which gives a positive start for the development of positive personality traits at subsequent stages of development and strengthening of the psychological health.

Thus, the third-year crisis is a crucial period of psychosocial development of a child. It requires special interaction and communication with the child by the parents, namely building an active object-oriented activity with the child and establishment of a positive emotional contact with him in the family, demonstration by the adults of the socially acceptable behavior, consideration of the age-specific and individual capacity of the child when lodging requirements to his actions in the family, on the street, and in other situations. All this contributes to the preservation and strengthening of the psychological health of the child.

Plans are underway to study the idea of the third-year crisis from the side of parents.

The article was prepared with the support of the Ministry of Education and Science of the Russian Federation within the framework of the Strategic Development Program "Pedagogical Staff for Innovative Russia".

\section{References}

Abrosimova, N. Age Stubbornness. The Third-Year Crisis. Date Views: 11.10.2014. http://www.2mm.ru/vospitanie/437.

Bolotova, A.K. and O.N. Molchanova, 2012. Developmental Psychology and Age-Specific Psychology. Moscow: NRU Higher School of Economics, pp: 528. Date Views: 11.10.2014. http://www.biblioclub.ru.

Dragunova, T.V., 1996. "Crisis" Was Explained Differently. In the Reader on Psychology, Compiled by Semeniuk, L.M. Moscow: Institute of Applied Psychology, pp: 237-239.

Elkonin, D.B., 1997. Mental Development during Childhood Ages. Eds., Feldstein, D.I. Moscow: Publishing House of the "Institute of Applied Psychology"; Voronezh: NPO "MODEK", pp: 416.

Fadeeva, O.V., 2011. Singularities of Dealing with Young Children in Groups of Short Stay. Modern Kindergarten, 8: 25-28.

Fadeeva, O.V., 2011. The Process of Psychological Support of Young Children in the Group of Short Stay. In the Proceedings of the International Scientific and Practical Conference: Educational Psychology in the XXI Century: Theory and Practice, 14-16 September. 2011. Volgograd: VGSPU "Peremena" Publishing House, pp: 219-220.

Goodman, R., H. Slobodskaya and G. Knyazev, 2005. Russian Child Mental Health: a Cross-sectional Study of Prevalence and Risk Factors. European Child and Adolescent Psychiatry, 14: 28-33.

Khukhlaeva, O.V., 2003. How to Maintain the Psychological Health of Adolescents: Guideline. Moscow: September, pp: 176.

MacNaughton, G. 2004. Doing Foucault in Early Childhood Studies: Applying Poststructural Ideas. Taylor \&, Francis, pp: 256. 
Malkina-Pykh, I.G., 2005. Age Crises: A Handbook of Practical Psychology. Moscow: Eksmo, pp: 896.

Nikorchuk, N., 2014. The Third-Year Crisis. Date Views: 10.10.2014. http://www.svetan.ru/krizis_trex_let.html.

Prokhorova, S.Yu. and E.B. Khizhova, 2012. Parents Meeting "The Role of the Family in Maintaining Mental Health of Children" Directory of Educational Psychologist: the Kindergarten, 3: 53-65.

Psychology of a Human from Birth to Death, 2002. Eds., Rean, A.A. Saint Petersburg: Praym, pp: 656

Ruskina, E.N., 2011. Opportunities of Achieving the Psychological Safety of a Personality under the Manipulative Influence. Humanities and Education, 4(8): 85-87.

Santrock, J., 1996. Child Development. Dubuque, IA: Brown and Benchmark Publishers, pp: 344.

Sears, R. and E. and H. Levin, 1957. Patterns of Child Rearing. Evanston, pp: 550.

Tomas, V.Yu., 2012. Tears and Whims. Date Views: 11.10.2014. http://deti.mail.ru/vopros/vrach/nevrolog_nevrologija/34503/

Vygotsky, L.S., 1997. Issues of Child Psychology. Saint Petersburg: Soyuz, pp: 224.

Vygotsky, L.S., 2004. Psychology of Human Development. Moscow: Smysl; Eksmo, pp: 1135.

Yashkova, A.N. and N.F. Sukhareva, 2011. Age Psychology: Study Guide. Saransk: Mordovian State Pedagogical Institute, pp: 101.

Yashkova, A.N., 2012. The Crises of Age Development and the Mental Health in Childhood. Scientists' Notes of the St. Petersburg State Institute of Psychology and Social Work, 18: 95-100. 